\title{
Empirical Scaling Laws for Crater Dimensions for Impacts into Solar Cells
}

\author{
K. G. Paul
}

Fachgebiet Raumfahrttechnik, TU München, 80333 München, Germany

L. Berthoud

European Space Agency, European Space Research and Technology Centre, 2200 AG Noordwijk, The Netherlands.

\section{Introduction}

The returned solar cells from the European Retrievable Carrier (EURECA) satellite and one Hubble Space Telescope Solar Array (HST-SA) acted as collector surfaces for microparticles in the vicinity of the Earth. Because only limited information on cratering formulae for solar cells was available from the literature, hypervelocity impact experiments on such samples were performed at the plasma drag accelerator facility of the Fachgebiet Raumfahrttechnik (LRT), TU München. The results from these experiments were combined with data from experiments performed during the Apollo program into a new scaling law relating particle parameters and impact crater dimensions on solar cell targets.

\section{Data Sources}

\subsection{Historic Data}

Concerns about meteoroid impact damage to windows in the course of the Apollo Program generated a series of test programs. These resulted mainly in penetration depth equations. Spall diameters were also investigated, though mainly in conjunction with investigations on lunar rocks.

\subsection{ESA Hypervelocity Impact Program Overview}

A notable gap existed in the particle size range of $10-100 \mu \mathrm{m}$ and insufficient data existed for larger sized projectiles (Berthoud, 1994). As part of the EURECA and Hubble Space Telescope post flight investigation programs, hypervelocity impact tests were performed using the plasma drag accelerator facility at the LRT, Munich, and the two stage light gas gun at Ernst-Mach-Institut, Freiburg. Rows six and seven in table 1 show the new data from LRT.

The sources of all data used are shown in table 1 and the coverage of the complete dataset is given in table 2. The impact angle is measured from the surface normal. 
Table 1. Data on hypervelocity impacts on glass surfaces used.

\begin{tabular}{|c|c|c|c|}
\hline Investigator & Projectiles & Target material & Velocities \\
\hline Roy et al., 1972 & $\begin{array}{l}\text { Fe, Si, LaB6 spheres, } \\
\mu \mathrm{m}-\text {-sized }\end{array}$ & $\begin{array}{l}\text { Apollo-type quartz } \\
\text { windows }\end{array}$ & $2-26.8 \mathrm{~km} / \mathrm{s}$ \\
\hline $\begin{array}{l}\text { Mandeville and } \\
\text { Vedder, } 1971\end{array}$ & $\begin{array}{l}\text { polystyrene spheres, } \\
\mu \mathrm{m} \text {-sized }\end{array}$ & glass surfaces & up to $12 \mathrm{~km} / \mathrm{s}$ \\
\hline Kuczera, 1985 & $\begin{array}{l}\text { glass spheres, tens of } \\
\mu \mathrm{m} \text {-sized }\end{array}$ & ECS solar panels & up to $10 \mathrm{~km} / \mathrm{s}$ \\
\hline Rott, 1988 & $\therefore$ & SILEX mirrors & up to $12 \mathrm{~km} / \mathrm{s}$ \\
\hline Paul, 1994 & $-"-$ & EURECA solar panels, & up to $15 \mathrm{~km} / \mathrm{s}$ \\
\hline Dirr, et al., 1995 & -"- & HST solar panels & $2-15 \mathrm{~km} / \mathrm{s}$ \\
\hline $\begin{array}{l}\text { Schäfer and } \\
\text { Schneider, } 1994\end{array}$ & $\begin{array}{l}\text { Aluminum, Glass, Ple- } \\
\text { xiglass, } \mathrm{mm} \text {-sized }\end{array}$ & EURECA solar panels & $5-6 \mathrm{~km} / \mathrm{s}$ \\
\hline
\end{tabular}

Table 2. Parameter range of the complete dataset.

\begin{tabular}{lllll} 
Parameter & Symbol & \multicolumn{2}{r}{ Range from ... to } & Unit \\
\hline Density & $\rho_{p}$ & 1.06 & 7.8 & {$\left[\mathrm{~g} / \mathrm{cm}^{3}\right]$} \\
Diameter & $d$ & $0.28 \cdot 10^{-4}$ & $114 \cdot 10^{-4}$ & {$[\mathrm{~cm}]$} \\
Mass & $m$ & $2.99 \cdot 10^{-14}$ & $2.017 \cdot 10^{-6}$ & {$[\mathrm{~g}]$} \\
Velocity & $v$ & $1.22 \cdot 10^{4}$ & $26.8 \cdot 10^{4}$ & {$[\mathrm{~cm} / \mathrm{s}]$} \\
Impact Angle & $\theta$ & 0 & 75 & {$\left[{ }^{\circ}\right]$}
\end{tabular}

\section{Scaling Laws}

(Fechtig et al., 1974) adopted the conchoidal cracking diameter equation from (Gault, 1972) for impacts into glass. This relationship is given in equation 1.

$$
D_{C o}=5 \cdot 10^{-4} \rho_{t}^{-0.5} \rho_{p}^{0.71} d^{1.13} v^{0.754}
$$

with $D_{C o}$ the conchoidal cracking diameter, $\rho_{t}$ and $\rho_{p}$ the target and particle density, $d$ the particle diameter, and $v$ the particle velocity. All units are [cgs].

After adding a term for the impact angle, a least error squared fit of the scaling law to the experimental data was performed. All constants were allowed to be modified except for the target density as the underlying data did not vary significantly enough to justify an optimization for this parameter. As can be seen in equation 2 , the modifications are minor. The major difference that can be seen is the influence of the impact angle $\theta$, measured from the surface normal, on the spall diameter while the central pit diameter is scarcely affected by it (coefficient 0.601 vs. 0.15 ).

$$
\begin{gathered}
D_{C o}=5 \cdot 10^{-4} \rho_{t}^{-0.5} \rho_{p}^{0.784} d^{1.077} v^{0.727} \cos ^{0.601} \theta \\
D_{P_{i t}}=1.12 \cdot 10^{-4} \rho_{t}^{-0.5} \rho_{p}^{0.743} d^{1.077} v^{0.726} \cos ^{0.150} \theta
\end{gathered}
$$

If $D_{C o}$ or $D_{P i t}$ are measured in terms of minimum and maximum diameters, we calculated the average diameter geometrically (i.e. $D_{C o}=\sqrt{D_{C o, \min } D_{C o, \max }}$ ) Equation 2 applies only to craters big enough to show signs of spallation, equation 3 only to craters small enough to have an intact central pit (Cour-Palais, 1987). 

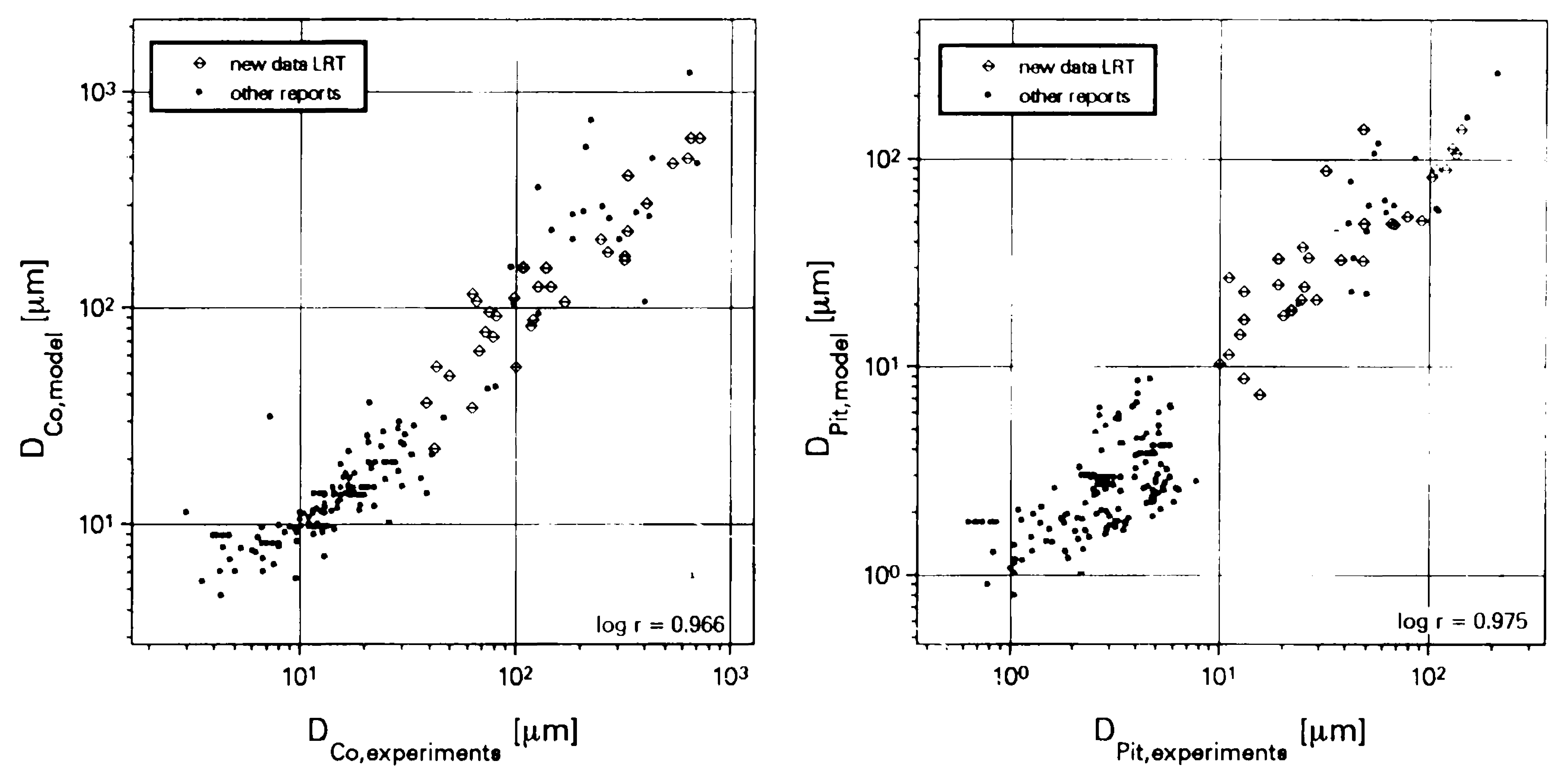

Figure 1. Comparison of models with actual data.

To aroid any side effects from finite target effects (the cover glass of the solar cells has a thickness of $150 \mu \mathrm{m}$ ), only data from impacts with a particle size smaller than $25 \mu \mathrm{m}$ were used to make sure that the criterion for semi-infinite cratering (McHugh \& Richardson, 1968) was still satisfied. Also, no data from impacts that showed no signs of spallation $\left(D_{P i t}=D_{C o}\right)$ were used for the spallation diameter fit.

The comparison between equations 2 and 3 and the experimental data is shown in figure 1 . The measured values are compared with the model values. The agreement of the spallation diameter relationship is very good for larger microcraters although they were not included in the data used for obtaining the fit. This may be due to the difference in diameter exponents of equation 1 and equations 2 and 3 of $d^{0.053}$. This is in accordance to (Cour-Palais, 1985), who suggested that $d_{c} / d_{p} \propto d_{p}^{0.056}$.

\section{Other Observations}

Keeping the issues of the absence of spallation for very small craters and the supralinearity effects in mind, it is interesting to look at the variation of the relative size of the two crater diameters discussed here. Figure 2 shows the development of the ratio $D_{C o} / D_{P i t}$ over $D_{P i t}$ for craters found on HST (Berthoud $\&$ Paul, 1995). The data were smoothed using a 20-datapoint floating average, i.e. $\frac{D_{C o, i}{ }^{*}}{D_{P i t, i}}=\frac{1}{21} \sum_{j=i-10}^{i+10} \frac{D_{C o, j}}{D_{P i t, j}}$.

When compared with germanium witness plate impact data from the leading surface of the Long Duration Exposure Facility (LDEF) (Paul, 1995), a similarity in the slope can be seen for craters with $D_{P i t}>10 \mu \mathrm{m}$, while there is a notable difference for smaller craters. This behaviour is yet unexplained but could be caused by ejecta from impacts into the structure of the HST satellite. Laboratory data has an average ratio $D_{C o} / D_{P i t}$ of $\approx 4$ (not shown). Possible 


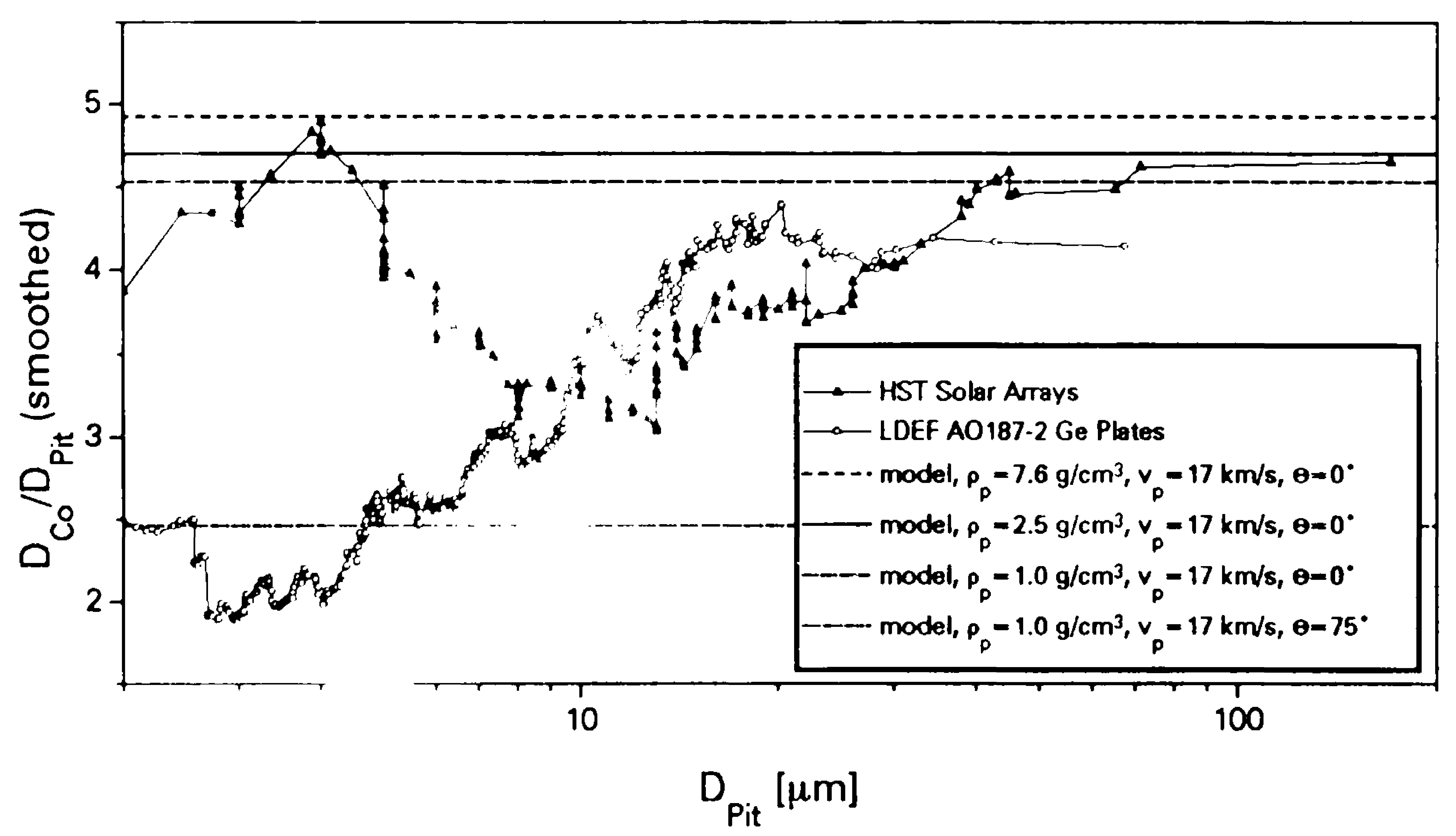

Figure 2. Change of normalized crater zone size with impact size.

causes may be differences in material properties or a change in particle density or impact conditions with impactor size.

\section{Summary}

Data from hypervelocity impact investigations on solar cells and previous work done on glasses were used to update the cratering equation by (Fechtig et al., 1974) to cover supralinearity and impact angle effects. The study of the morphology of impacts on brittle materials retrieved from space might give insight to changes into physical properties of various size particles.

\section{References}

Berthoud, L. 1994, ESA-SP 368

Cour-Palais, B. G. 1985, NASA CP-2360

Cour-Palais, B. G. 1987, Int. J. Impact Engng., 5

Fechtig, H., Gentner, W., Hartung, J. B., Nagel, K., Neukum, G., Schneider, E., Storzer, D. 1974, NASA SP-370

Gault, D. E., Hörz, F., Hartung, J. B. 1972, Geochim. Cosmochim. Acta, 3, 3

Kuczera H. 1985, ESA contract report No. 6055/85/NL/AN

Mandeville, J.C., Vedder J. F. 1971, Ea. Planet. Sci. Let., 11

McHugh, A. H., Richardson A. V. 1968, STR 241, North American Aviation

Paul, K. G 1994, ĖSA purchase order report 142358

Paul, K. G. 1995, NASA CP-3275

Rott, M. 1988, MATRA contract report No. 88/cpt/6259t/ic/lb

Roy, N. L., Slattery, J. C., Friichtenicht, J. F. 1972, TRW Report 20921-600i$\mathrm{R} 0-00$

Schäfer F., Schneider, E. 1994, ESA purchase order report 142359 